\title{
Body-checking and its association with nutritional status in young adults
}

\author{
Pedro Henrique Berbert de Carvalho1, Valter Paulo Neves Miranda², Silvia Eloiza Priore², \\ Fernanda da Costa Oliveira 3 , Maria Elisa Caputo Ferreira ${ }^{4}$
}

' Federal University of Juiz de Fora (UFJF), Campus Governador Valadares, Juiz de Fora, MG, Brazil.

2 Department of Nutrition, Federal University of Viçosa (UFV), Viçosa, MG, Brazil.

3 Faculty of Physical Education and Sport, UFJF, Juiz de Fora, MG, Brazil.

4 Department of Psychology, UFJF, Juiz de Fora, MG, Brazil.

Received: 10/28/2014 - Accepted: 3/23/2015

DOI: 10.1590/0101-60830000000044

\begin{abstract}
Background: The body-checking is a frequent behavior observed in young adults. It is associated with body dissatisfaction and inappropriate eating attitudes. However, its association with nutritional status remains unclear. Objectives: This study aimed to assess the association between body-checking behavior and nutritional status. Methods: We conducted a cross-sectional study with 587 (311 men) undergraduate students from the city of Juiz de Fora - Minas Gerais. The frequency of body-checking behavior was assessed by Body Checking Questionnaire and Male Body Checking Questionnaire; and inappropriate eating attitudes by Eating Attitudes Test-26. Body weight and height were self-reported. Descriptive, Chi-square test of association and Multiple Correspondence Analysis were done, adopting a statistical significant level of 5\%. Results: Association was found between body-checking behavior, nutritional status and gender $\left(\chi^{2}(64)=3219.88 ; \mathrm{p}<0.001\right)$. The Multiple Correspondence Analysis demonstrated association between the nutritional status categories low weight, eutrophia and overweight conjointly with low and moderate body-checking categories. Obesity and high body-checking, in turn, were inversely associated. Discussion: There was an association between nutritional status and the frequency of body-checking behaviors in young adults of both genders. Body-checking is a behavior that deserves attention and monitoring in epidemiological and clinical practices.
\end{abstract}

Carvalho PHB et al. / Arch Clin Psychiatry. 2015;42(2):33-7

Keywords: Body-checking, nutritional status, gender, multivariate analysis.

\section{Introduction}

The concern with physical appearance and body image is a reality in both developed and developing countries, increasing investment on the body and the adoption of body change behaviors ${ }^{1}$. Nevertheless, some authors pointed that ${ }^{2,3}$, seeking good physical appearance and health simultaneously leads to unclear boundaries, where health and aesthetic motives juxtapose each other interchangeably.

The process of demographic and epidemiological transition is prone to population aging and to the increasing prevalence of chronic non-communicable diseases ${ }^{4}$. Malnutrition was reduced and the prevalence of overweight and obesity has increased due to the adoption of sedentary lifestyle and consumption of high-fat foods 5 . As a consequence of body composition changes resulting from unhealthy living habits, chronic non-communicable diseases are becoming a public health problem assuming epidemic proportions ${ }^{6}$.

Studies have shown that overweight and obese individuals have psychological disorders, such as lower body satisfaction and self-esteem, greater social anxiety, and exhibiting major depressive symptoms than those with underweight and adequate weight ${ }^{7,8}$. In order to modify the body, various strategies have been adopted, such as excessive physical exercise, restrictive diets, use of dietary supplements, as well as the use/abuse of anabolic steroids, laxatives and vomiting ${ }^{9,10}$. It is important to note that some of these practices are directly linked to health damage, while others have potential for harm if not managed correctly (i.e., excessive physical exercise and use of dietary supplements) ${ }^{10}$.

Body-checking is a behavioral manifestation of body dissatisfaction and overconcern with shape and weight ${ }^{11}$ and includes any behavior oriented to verify the body appearance and physical state held constant by means of weighing, measuring body parts (i.e., waist and abdomen in women and biceps and chest in men) and analysis of the body in mirror. Such behaviors are used as a source of information about the success or failure in controlling body weight and shape, and its frequency is associated with body dissatisfaction, purging behaviors and restrictive diets ${ }^{12-16}$.

However, the study of body-checking behavior is recent and its association with nutritional status remains unclear. It is possible that underweight, eutrophic, overweight and obese individuals showed differences in frequency of body-checking behavior, either to control body weight for health reasons, or even to the desire to modify their physical appearance and to increase your body satisfaction. Thus, the aim of this research was to associate the frequency of body-checking behavior with the nutritional status of young adults of both genders.

\section{Methods}

\section{Study design and participants}

This cross-sectional study ${ }^{17}$ was developed with a random sample of 587 undergraduate students ( 276 women and 311 men) of the Federal University of Juiz de Fora (UFJF) - Minas Gerais.

To participate, individuals must be regularly enrolled in any period of the courses of the UFJF, be older than 18 years old and agree to participate voluntarily in the study. Individuals who scored greater than or equal to 21 points on the Eating Attitudes Test- $26^{18}$ were excluded. Such cutoff point is used as an indicator of abnormal eating attitudes and risk for development of eating disorder. We adopted this strategy since individuals with eating disorders present higher frequency of body-checking behavior when compared with a non-clinical population ${ }^{12,14}$.

The sample size calculation was performed considering a confidence level equal to $95 \%, 5 \%$ of maximum error of estimation, and unknown prevalence of phenomenon (body-checking behavior) ${ }^{17}$. The value obtained, already corrected for finite samples was 378 individuals. Twenty percent was added to effect of sample loss, yielding a final value of 454 individuals. 
The study was approved by the Ethics in Research Committee of the UFJF, according to the protocol 2193.253.2010. All ethical principles established by the Health National Council Resolution 196 from October 10, 1996, were respected.

After approval of the project, the researchers established contact with teachers of the UFJF to explain the entire procedure and request authorization for intervention during the initial period of classes. On the day of data collection, the researchers explained the objectives and procedures of the study to the participants and distributed the forms. Thus, those who voluntarily agreed to participate and signed the consent answered the questionnaires.

\section{Assessment measures}

The Brazilian version of the Body Checking Questionnaire (BCQ) ${ }^{19}$ was used to evaluate the body-checking behavior in women. The BCQ is an easily understandable 5 -item Likert scale $(1=$ never to $5=$ very often) on which the individual rates the frequency of 12 sentences related to body-checking behavior. The instrument score ranges from 12 to 60 points. The higher the score, the more frequent is the bodychecking behavior. The Brazilian version achieved adequate internal consistency and factor structure ${ }^{19}$. The internal consistency of the BCQ obtained in the present sample was adequate (Cronbach's alpha $=0.85$ ).

To assess body-checking behavior in males, the Male Body Checking Questionnaire (MBCQ) ${ }^{20}$ was used. The MBCQ is a selfreport instrument with 19 sentences answered on a 5-item Likert scale $(1=$ never to $5=$ very often $)$. The score ranges from 19 to 95 points, and the higher the score, the more frequent are behaviors related to body-checking ${ }^{20}$. The MBCQ was developed as an alternative to BCQ to enable the evaluation of body-checking behaviors in men. The Brazilian version achieved adequate internal consistency (Cronbach's alpha $=0.93)^{20}$ and in this sample corresponded to 0.94 .

The Eating Attitudes Test-26 (EAT-26) was used to assess the inappropriate eating attitudes ${ }^{18}$. The instrument consists of 26 sentences answered on a 6-item Likert scale with responses ranging from always ( 3 points) to never ( 0 point), except for question 25 , which has an inverse score. Score greater than or equal to 21 points is an indicator of possible risk behavior for eating disorders (EAT-26 positive), and the presence of abnormal eating patterns ${ }^{18}$. The Brazilian version had good internal consistency ${ }^{18}$, and in the present sample was equal to 0.88 ( 0.87 for women and 0.88 for men).

The assessment of nutritional status was evaluated through the body mass index (BMI), which was calculated using self-reported data of body mass and height. Subjects were grouped according to the classification established by the World Health Organization ${ }^{21}-$ $\mathrm{BMI}<18.5 \mathrm{~kg} / \mathrm{m}^{2}$ (underweight); BMI $18.5-24.9 \mathrm{~kg} / \mathrm{m}^{2}$ (eutrophic); BMI $25-29.9 \mathrm{~kg} / \mathrm{m}^{2}$ (overweight); and BMI $>29.9 \mathrm{~kg} / \mathrm{m}^{2}$ (obesity).

\section{Statistical analysis}

All data were stored in a database and analyzed using SPSS software v. 16.0. Descriptive statistics (mean and standard deviation) on the age of the participants was performed. Nutritional status, inappropriate eating attitudes and body-checking behaviors were described by absolute and relative frequencies. Inferential statistics were applied to report the internal consistency (Cronbach's alpha) of the questionnaires. Alpha higher than 0.70 was considered adequate ${ }^{22}$.

Multiple Correspondence Analysis (MCA) were performed, following the geometric data analysis ${ }^{23,24}$. Associations between categories of different variables (body-checking behaviors, nutritional status and gender) were obtained by the MCA.

Through graphic representation, it is possible to interpret associations according to the positions of the categories of each variable in the multidimensional plan. The distance between the positions of each category is a chi-square distance, allowing the analysis of association between them. In order to obtain plans that represent the configuration categories of variables in space, we calculate a set of factorial axes (dimensions), each maximizing a portion of the data variability. This set of axes define a multidimensional space and, usually, one can use a noticeable size, up to three axes to analyze the position of the points in space ${ }^{23,24}$.

The MCA is based on categorical data and utilizes observed frequency ${ }^{24}$. Thus variables as gender (female and male) and nutritional status (underweight, eutrophia, overweight and obesity) were classified. The scores of BCQ and MBCQ were analyzed according to tertiles. Women were classified (BCQ) in low (12-27 points), moderate (28-43 points) and high body-checking (44-60 points); while men (MBCQ) in low (19-44 points), moderate (45-69 points) and high body-checking (70-95 points).

As a premise for the fulfillment of the MCA, Chi-square test was performed to ascertain if there was independence between variables ${ }^{24}$. For all analyzes, results were considered significant only if $\mathrm{p}<0.05$.

\section{Results}

\section{Descriptive analysis}

A total of 587 undergraduate students (276 women and 311 men) were recruited. Eighty-two participants (62 women and 20 men) from the original sample were excluded due to the presence of risk factors for eating disorders (EAT-26 positive). We analyzed data from the remaining 505 participants with an average age of 20.19 (SD = 2.41 years) among women and $21.57(\mathrm{SD}=3.79$ years $)$ among men

It was observed underweight in $14.46 \%(\mathrm{n}=73,60$ women and 13 men), eutrophia in $63.76 \%(n=322,134$ women and 188 men $)$, overweight in $18.22 \%(\mathrm{n}=92,12$ women and $80 \mathrm{men})$, and obesity in $3.56 \%(\mathrm{n}=18,8$ females and 10 males) of the participants (Table 1$)$.

\section{Multiple correspondence analysis}

The results of the MCA demonstrated that three factorial axes were sufficient for analyzing the data, explaining $58.88 \%$ of the total data variability. Visual analysis of screeplot (graphic not shown) confirmed the maintenance of the three factorial axes (dimensions). Considering the absolute contributions of each variable in the composition of each dimension, elucidated in table 2 , it is observed that the first dimension is formed primarily by: male and female, underweight and overweight. The categories that mostly contributed to the formation of the second dimension are: obesity and high body-checking; while for the third dimension was comprised by eutrophia, low and moderate body-checking.

In figure 1 we have the geometric representation of the categories of the variables in the factorial plan, with the first two dimensions. The first, which explains $23.83 \%$ of the variability of the data, separates females from males, and the underweight from the overweight. On the negative side of dimension 1 are the group: female, underweight and moderate body-checking. Positioned on the positive side are the opposite characteristics: male, overweight and obesity, low and high body-checking. The eutrophia category is also on the positive side, however, its chi-square distance to ground zero axis is minimal $(0.02)$.

The second dimension, which explains $18.21 \%$ of the variability of the data, separates the obesity from the high body-checking. On the negative side of this dimension are: male, eutrophia and overweight and also moderate body-checking. On the opposite side are situated: female, underweight and obesity, and also low and high body-checking. The third dimension, which explains $16.84 \%$ of the variability of the data, separates low and moderate body-checking from eutrophia. On the negative side are: male, underweight, overweight and obesity and low body-checking. On the positive side are: female, normal weight, moderate and high body-checking.

Associations between categories of variables can be evaluated by analyzing the proximity of the points in figures 1 and 2 . Thus, in figure 1, it can be seen that the category female located in the left quadrant is formed by those with underweight and moderate body-checking. Meanwhile, the male category, located on the right quadrant is composed of overweight and low body-checking. It is still observed in figure 1 that eutrophia and low body-checking are between male and female dividing these two categories almost similarly, and thus being associated with both genders. 
Table 1. Percentage distribution of gender and nutritional status according to body-checking behavior frequency

\begin{tabular}{|c|c|c|c|c|}
\hline \multirow[t]{2}{*}{ Variables } & \multirow[t]{2}{*}{$\mathrm{N}(\%)$} & \multicolumn{3}{|c|}{ Body-checking frequency* } \\
\hline & & Low & Moderate & High \\
\hline \multicolumn{5}{|l|}{ Gender } \\
\hline Female & $214(42.38 \%)$ & $166(40.48 \%)$ & $48(53.33 \%)$ & $0(0 \%)$ \\
\hline Male & $291(57.62 \%)$ & $244(59.52 \%)$ & $42(46.67 \%)$ & $5(100 \%)$ \\
\hline \multicolumn{5}{|l|}{ Nutritional status } \\
\hline Underweight & $73(14.46 \%)$ & $59(14.39 \%)$ & $14(15.55 \%)$ & $0(0 \%)$ \\
\hline Eutrophia & $322(63.76 \%)$ & $260(63.41 \%)$ & $59(65.55 \%)$ & $3(60 \%)$ \\
\hline Overweight & $92(18.22 \%)$ & $75(18.29 \%)$ & $16(17.78 \%)$ & $1(20 \%)$ \\
\hline Obesity & $18(3.56 \%)$ & $16(3.91 \%)$ & $1(1.12 \%)$ & $1(20 \%)$ \\
\hline
\end{tabular}

* Significant to $p<0.05$. Test of independence to conducting the analysis of multiple correspondence. Chi-square test $-\chi 2(64)=3219.88 ; p<0.001$.

Table 2. Absolute contribution (mass, quality and inertia point) of variables in the composition of each factor on multiple correspondence analysis (geometric display)

\begin{tabular}{|c|c|c|c|c|c|}
\hline & Mass & Quality & Inertia D1 & Inertia D2 & Inertia D3 \\
\hline \multicolumn{6}{|l|}{ Gender } \\
\hline Female & 0.1413 & 0.7025 & 0.2785 & 0.0059 & 0.0001 \\
\hline Male & 0.1921 & 0.7025 & 0.2048 & 0.0044 & 0.0001 \\
\hline \multicolumn{6}{|c|}{ Nutritional status } \\
\hline Underweight & 0.0482 & 0.6343 & 0.2685 & 0.0049 & 0.1517 \\
\hline Eutrophia & 0.2125 & 0.4818 & 0.0002 & 0.0059 & 0.1661 \\
\hline Overweight & 0.0607 & 0.5568 & 0.1712 & 0.0563 & 0.1476 \\
\hline Obesity & 0.0119 & 0.5976 & 0.0027 & 0.5194 & 0.0050 \\
\hline \multicolumn{6}{|l|}{ Body-checking } \\
\hline Low & 0.2706 & 0.5414 & 0.0037 & 0.0074 & 0.0875 \\
\hline Moderate & 0.0594 & 0.5428 & 0.0312 & 0.0976 & 0.2918 \\
\hline High & 0.0033 & 0.5389 & 0.0392 & 0.2983 & 0.1501 \\
\hline
\end{tabular}

D1: dimension 1; D2: dimension 2; D3: dimension 3.

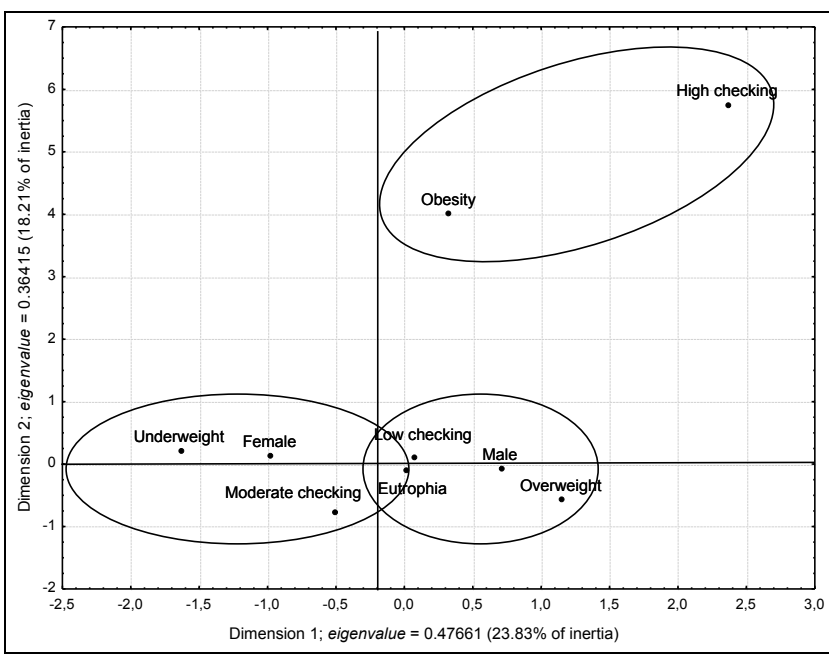

Figure 1. Distribution of gender, nutritional status and body-checking resulting from multiple correspondence analysis, in dimensions 1 and 2.

Still on the same figure (Figure 1) it can be observed a separation of the obesity and high body-checking of the others categories. However, as seen in table 2 , these categories are better represented in the second dimension, illustrated in figure 2 , with the third dimension. In this figure you can see the spacing of these two variables from the other. However, figure 2 shows that obesity and high body-checking are in opposite quadrants. It is also evident in figure 2 the association of eutrophia with low and moderate body-checking.

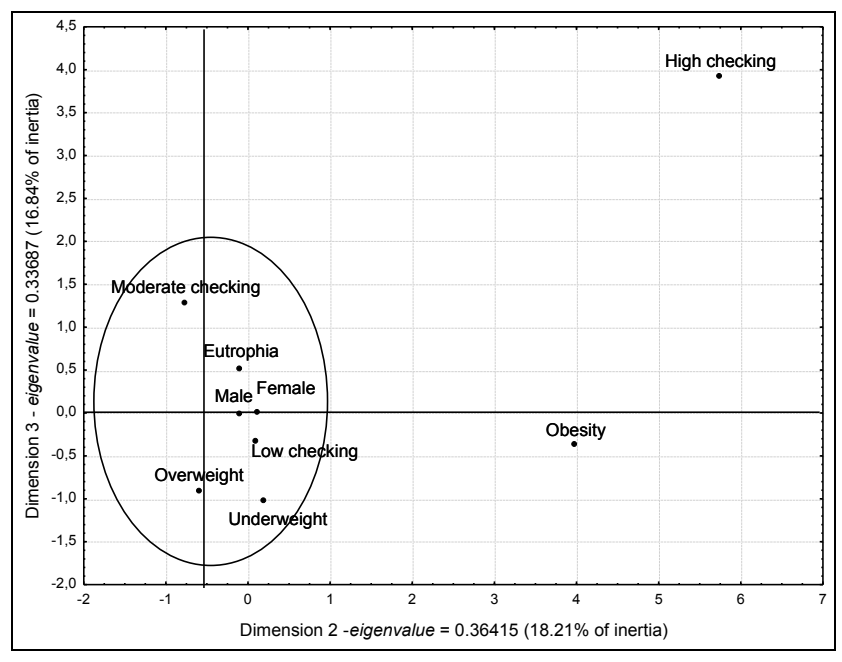

Figure 2. Distribution of gender, nutritional status and body-checking resulting from multiple correspondence analysis, in dimensions 2 and 3.

\section{Discussion}

This study sought to identify possible associations between the frequency of body-checking behavior and nutritional status of young adults of both genders. The method of MCA was able to demonstrate associations and similarities of the categories analyzed, by facilitating, as the proposed by the method itself, the visualization of data in a geometric space with chi-square distances ${ }^{24}$. Unlike other existing 
techniques of dependence in multivariate data analysis, in MCA, considered a technique of interdependence, the solution is based on existing data, without the possibility of modifying the dependency between the categories analyzed ${ }^{24}$.

According to the results of the MCA there was a linear relationship between the frequency of body-checking behaviors and nutritional status (Figures 1 and 2). Those individuals with underweight, eutrophia and overweight had a higher association with low and moderate body-checking. Specifically, around $80 \%$ of these individuals demonstrated low body-checking behaviors, while $18 \%$ showed moderate body-checking (Table 1). Such pattern of distribution was lost when approaching obese individuals, where different frequency values of body-checking (90\% low and 5\% moderate body-checking) were observed when compared to other categories.

This result confirms the hypothesis that body-checking behaviors may differ between groups by nutritional status. However, this difference was observed only in the obese group. According to Fairburn ${ }^{25}$, the more the individual observes his body parts he/she does not like, the more dissatisfied he/she becomes. It raises the possibility of adoption of inappropriate eating attitudes and also the adoption of deleterious health strategies. To deal with this body dissatisfaction, serving as a coping strategy, some individuals adopt an opposite behavior to checking, called "body avoidance behavior"25-27. Body avoidance is considered a response to thoughts and emotions related to events and actions that bring a deep depreciation or body dissatisfaction ${ }^{25}$. It is described as an action of concealing the body, accomplished through the use of loose clothes and dark colors (i.e., black), avoidance of social situations and contact with other individuals.

In a study with obese individuals Reas et al. ${ }^{26}$ concluded that there are periods of alternations between body-checking behaviors and avoidance. According to the authors, obese individuals seek to accommodate information obtained about their body weight and shape by interchange of body-checking and avoidance behaviors.

Grilo et al. ${ }^{27}$ also identified the alternation of these behaviors in obese seeking bariatric surgery. The authors highlight the relationship between high frequency of adoption of body-avoidance behaviors and binge eating, which contrasts with the relationship between high dietary restriction and body-checking.

The MCA also showed (Figure 1) an association between gender and body-checking. Women seem more likely to use a moderate body-checking frequency compared to men, who demonstrate more low body-checking frequency. Low body-checking behavior was present in $77.57 \%$ of female individuals and in $83.85 \%$ of males. Meanwhile, moderate body-checking was present in $22.43 \%$ and $14.43 \%$ of females and males, respectively. By using the same instruments applied in this research (BCQ and MBCQ), Alfano et al. ${ }^{15}$ identified significant differences in the frequency of body-checking behavior between genders. University female students showed higher frequency of body-checking behavior than males.

Body-checking behavior is related to the adoption of inappropriate eating behaviors, which is known to be harmful to health, such as extreme food restriction ${ }^{12-16}$. Patients diagnosed with anorexia nervosa and bulimia nervosa demonstrate a higher frequency of this behavior than a non-clinical population ${ }^{12-14}$.

Kachani et al. ${ }^{14}$ compared the frequency of body-checking behavior among Brazilian women with eating disorders (anorexia and bulimia nervosa) and a control group (non-clinical sample). Patients with eating disorders, especially with bulimia nervosa exhibited higher frequency of body-checking compared to the control group. The most common way to check the body was through the mirror, while the least was body weighing.

Unlike the present study, Kachani et al. ${ }^{14}$ do not identified association between nutritional status (BMI) and the body-checking behavior frequency. This different result can be explained by the characteristic of the group evaluated. As stated previously, patients with anorexia and bulimia nervosa have a higher frequency of body-checking behavior than individuals without the disorder ${ }^{12}$. In addition, to be diagnosed with anorexia nervosa women must have a BMI below the recommended for Health Institutions, which limits the variability of BMI among this sample for the statistical association analysis. Such a situation occurs in the non-clinical population $(\mathrm{n}=$ 40) used by the researchers ${ }^{14}$.

Fairburn et al..$^{28}$ indicated that body-checking behavior is used by individuals as a means of evaluation of the own body, for example in order to get answers about the effectiveness of a program to reduce food intake (diet) or physical exercise for weight loss. An important outcome of Kachani's research ${ }^{14}$ is the differentiation of the reasons that lead to body-checking behavior. Women with anorexia nervosa use this behavior to obtain objective information about the body and to feel that they have control over it, while those with bulimia nervosa seek comfort and safety. The control group (non-clinical) showed less motivation when compared to the clinical group and similarity among the reasons to check your own body.

In addition, data from the present study allowed us to conclude that women are more prone to body-checking behaviors, possibly greater need for control over the body, and higher necessity of body comfort than men. Male individuals in turn seem to exhibit less frequently this behavior and therefore would be less likely to adopt deleterious health behaviors such as vomiting, use of laxatives and the practice of extreme restrictive diet.

As stated by Fairburn et al. ${ }^{28}$, frequent body-checking increases body dissatisfaction and leads to food restriction. In this sense, individuals with underweight, eutrophia and overweight seem to adopt body-checking as a way of control over the body or even a direct form to obtain information about their weight and body shape. Such a strategy of body-care serves as a parameter of success/ failure in weight control and must be accompanied and guided by professionals dealing with this individual. However, similar attention should be available to obese individuals. Although these individuals present low body-checking, its high avoidance behavior can forward for binge eating, causing health damage ${ }^{6}$.

For these reasons, researchers point to the need to monitor these behaviors in clinical practice ${ }^{14,25,28}$. Considering the role in the etiology and maintenance of beliefs and cognitive dysfunctions in patients with eating disorders, body-checking behavior should be considered target in the treatment of these patients and also a strategy for monitoring non-clinical population ${ }^{12,14,25}$.

This paper presented advances in the identification of the association of body-checking behaviors and nutritional status. However, some limitations were worth mentioning. First, the sample used was a convenience sample of undergraduate students. Results may not generalize to different geographical Brazilian regions. Second, the cross-sectional design. This design didn't allow to conclude whether there is alternation between body-checking and body-avoidance behaviors in this population, as suggested by other studies ${ }^{26,27}$. Third, possible mental disorders other than eating disorders were not systematically assessed/excluded among this study's participants. EAT-26 was used to assess risk behavior for eating disorders. Thus, biases due to the presence of psychiatric conditions cannot be fully addressed. Lastly, although it is a valid method for assessing the nutritional status, BMI was self-reported and may not be suitable for evaluating aspects of male body image, since in this population a concern with muscularity is a crucial aspect of body change behaviors ${ }^{29}$.

Despite these limitations the present study contributed to the understanding of the association between body-checking behavior and nutritional status. In particular, we highlight the association between nutritional status and the frequency of body-checking in young adults of both genders. Obese individuals have a higher frequency of low body-checking. Women exhibited greater relationship with moderate body-checking, while men with low body-checking.

Body-checking behavior deserves observation and monitoring in epidemiological and clinical practice, due to known interference of this variable on the health of individuals. More studies should be conducted to study the cause-effect relationship between the factors that lead to attitudes of body-checking performed on children, adolescents, adults and the elderly. 


\section{Acknowledgements}

We gratefully acknowledge the instrumental support of the Laboratório de Estudos do Corpo (LABESC). We thank the study participants and the Federal University of Juiz de Fora (UFJF) for the partnership in this study.

\section{References}

1. Swami V, Frederick DA, Aavik T, Alcalay L, Allik J, Anderson D, et al. The attractive female body weight and female body dissatisfaction in 26 countries across 10 world regions: results of the International Body Project I. Pers Soc Psychol Bull. 2010;36(3):309-25.

2. Castro MR, Carvalho RS, Ferreira VN, Ferreira MEC. Função e imagem corporal: uma análise a partir do discurso de mulheres submetidas à cirurgia bariátrica. Rev Bras Ciênc Esporte. 2010;32(2-4):167-83.

3. White J, Halliwell E. Examination of a sociocultural model of excessive exercise among male and female adolescents. Body Image. 2010;7(3):22733.

4. Geraldo JM, Alfenas RCG. Papel da dieta na prevenção e no controle da inflamação crônica: evidências atuais. Arq Bras Endocrinol Metab. 2008;52(6):951-67.

5. Batista Filho M, Rissin A. A transição nutricional no Brasil: tendências regionais e temporais. Cad Saude Publica. 2003;19(1):181-91.

6. American Diabetes Association. The prevention or delay of type 2 diabetes (Position Statement). Diabetes Care. 2004;27(1):47-54.

7. Carels RA, Burmeister J, Oehlhof MW, Hinman N, Leroy M, Bannon E, et al. Internalized weight bias: ratings of the self, normal weight, and obese individuals and psychological maladjustment. J Behav Med. 2012;35(1):86-94.

8. Latner JD, Wilson RE. Obesity and body image in adulthood. In: Cash TF, Smolak L, editors. Body image: a handbook of science, practice and prevention. 2. ed. New York: The Guilford Press; 2011. p. 189-97.

9. Nunes MA, Barros FC, Olinto MTA, Camey S, Mari JDJ. Prevalence of abnormal eating behaviors and inappropriate methods for weight control in young women from Brazil: a population-based study. Eat Weight Disord. 2003;8(2):100-6.

10. Cafri G, Thompson JK, Ricciardelli L, McCabe M, Smolak L, Yesalis C. Pursuit of the muscular ideal: physical and psychological consequences and putative risk factors. Clin Psychol Rev. 2005;25(2):215-39.

11. Walker DC, Anderson DA, Hildebrandt T. Body checking behaviors in men. Body Image. 2009;6(3):164-70.

12. Shafran R, Fairburn CG, Robinson P, Lask B. Body checking and its avoidance in eating disorders. Int J Eat Disord. 2004;35(1):93-101.

13. Mountford V, Haase A, Waller G. Body checking in the eating disorders: associations between cognitions and behaviors. Int J Eat Disord. 2006;39(8):708-15.
14. Kachani AT, Brasiliano S, Cordás TA, Rochgraf PB. Body checking and associated cognitions among Brazilian outpatients with eating disorders and non-psychiatric controls. Body Image. 2013;10(1):127-30.

15. Alfano L, Hildebrandt T, Bannon K, Walker C, Walton KE. The impact of gender on the assessment of body checking behavior. Body Image. 2011;8(1):20-5.

16. Haase AM, Mountford V, Waller G. Associations between body checking and disordered eating behaviors in nonclinical women. Int J Eat Disord. 2011;44(5):465-8.

17. Thomas JR, Nelson JK, Silverman SJ. Métodos de pesquisa em atividade física. 6. ed. São Paulo: Artmed; 2012.

18. Nunes MA, Camey S, Olinto MTA, Mari JJ. The validity and 4-year testretest reliability of the Brazilian version of the Eating Attitudes Test-26. Braz J Med Biol Res. 2005;38(11):1655-62.

19. Campana ANNB. Tradução, adaptação transcultural e validação do "Body Image Avoidance Questionnaire (BIAQ)" e do "Body Checking Questionnaire (BCQ)" para a língua portuguesa no Brasil. Campinas. Dissertação [Mestrado em Educação Física] - Universidade Estadual de Campinas; 2007.

20. Carvalho PHB, Conti MA, Cordás TA, Ferreira MEC. Tradução para o português (Brasil), equivalência semântica e consistência interna do Male Body Checking Questionnaire (MBCQ). Rev Psiquiatr Clin. 2012;39(2):74-5.

21. World Health Organization. WHO Expert Committee on Physical Status: the use and interpretation of anthropometry physical status. Geneva: World Health Organization; 1995 (WHO Technical Report Series, v. 854).

22. Cortina JM. What is coefficient alpha? An examination of theory and applications. J Applied Psychol. 1993;78(1):98-104.

23. Clausen SE. Applied correspondence analysis: an introduction. Quantitative Applications in the Social Sciences. Thousand Oaks, CA: Sage University Papers Series; 1998.

24. Hair Júnior JF, Anderson RE, Tatham RL, Black WC. Análise multivariada de dados. 5. ed. Porto Alegre: Bookman; 2005.

25. Fairburn CG. Cognitive behavior therapy and eating disorders. New York: The Guilford Press; 2008.

26. Reas DL, Grilo CM, Masheb RM, Wilson GT. Body checking and avoidance in overweight patients with binge eating disorder. Int $J$ Eat Disord. 2005;37(4):342-6.

27. Grilo CM, Reas DL, Brody ML, Burke-Martindale CH, Rothschild BS, Masheb RM. Body checking and avoidance and the core features of eating disorders among obese men and women seeking bariatric surgery. Behav Res Ther. 2005;43(5):629-37.

28. Fairburn CG, Shafran R, Cooper Z. A cognitive behavioral theory of anorexia nervosa. Behav Res Ther. 1999;37(1):1-13.

29. Carvalho PHB, Ferreira MEC, Kotait M, Teixeira PC, Hearst N, Cordás TA, et al. Equivalências conceitual, semântica e instrumental: análises preliminares da versão em português (Brasil) da Male Body Dissatisfaction Scale (MBDS). Cad Saúde Pública. 2013;29(2):403-9. 